\title{
Removal of Methylene Blue by Modified Carbon Prepared from the Sambucus Nigra L. plant
}

\author{
Mahboobeh Manoochehri ${ }^{\star}$ and Khadijeh Amooei \\ Department of Chemistry, Central Tehran Branch, Islamic Azad University Tehran, Iran
}

\section{Article Info}

Received 7 July 2012

Accepted 1 November 2012

*Corresponding Author

E-mail: dr.manoochehri@yahoo.com

\section{Open Access}

DOI: http://dx.doi.org/

10.5714/CL.2012.14.1.027

This is an Open Access article distributed under the terms of the Creative Commons Attribution Non-Commercial License (http://creativecommons.org/licenses/ by-nc/3.0/) which permits unrestricted non-commercial use, distribution, and reproduction in any medium, provided the original work is properly cited.

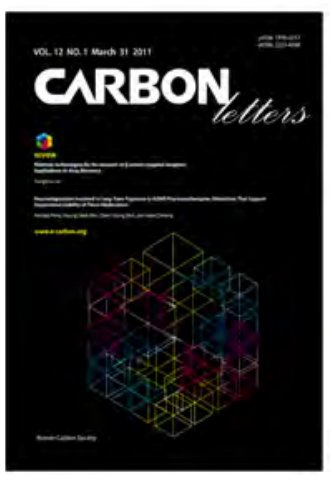

http://carbonlett.org

pISSN: $1976-4251$

elSSN: 2233-4998

Copyright $\odot$ Korean Carbon Society

\begin{abstract}
An increase in population initiating rapid industrialization was found to consequently increase the effluents and domestic wastewater into the aquatic ecosystem. In this research the potentialities of Sambucus nigra L. (SNL) plant in the remediation of water, contaminated with methylene blue (MB), a basic dye were investigated. SNL was chemically impregnated with $\mathrm{KHCO}_{3}$. Operating variables studied were $\mathrm{pH}$, amount of adsorbent and contact time. In general, $\mathrm{pH}$ did not have any significant effect on colour removal and the highest adsorption capacity was obtained in $0.035 \mathrm{~g} \mathrm{MB} / \mathrm{g}$-activated carbon. The Langmuir, Freundlich, Temkin and Dubinin-Radushkevich adsorption models were applied to describe the equilibrium isotherms. The adsorption isotherm data were fitted to the Temkin isotherm. The mass transfer property of the sorption process was studied using Lagergren pseudo-firstorder and chemisorption pseudo-second-order kinetic models. The sorption process obeyed the pseudo-second-order kinetic model. The surface area, pores volume and diameter were assessed by the Brunauer-Emmett-Teller and Barrett-Joyner-Halenda methods. The results were compared to those from activated carbon (Merck) and an actual sample. The results indicate that SNL can be employed as a natural and eco-friendly adsorbent material for the removal of dye $\mathrm{MB}$ from aqueous solutions.
\end{abstract}

Key words: adsorption, industrial effluent, activated carbon, methylene blue, Sambucus nigra $\mathrm{L}$.

\section{Introduction}

Dyes are synthetic aromatic water-soluble dispersible organic colorants with potential applications in various industries. The use of dyestuff materials has increased gradually due to the tremendous increase in industrialization and due to the general desire for color in everyday objects [1]. Dyes are used extensively in the paper, textile, leather, pharmaceutical, food, cosmetics, and printing industries [2,3]. The discharge of colored waste is not only damaging the aesthetic nature of the receiving streams, but also it may be toxic to the aquatic life in those streams. In addition, color interferes with the transmission of sunlight into a stream and therefore reduces the photosynthetic action [4]. Various treatment methods, such as physical, physic-chemical, biological and chemical processes have been investigated for treating dye-bearing effluents [5]. The adsorption technique has proved to be an excellent method to treat effluents, offering advantages over conventional processes, especially from an environmental point of view [6,7]. Adsorption is considered to be superior to other techniques owing to its low cost, simple design, good availability, and its ability to treat dyes in more concentrated form. Activated carbon is the most widely used adsorbent, showing great success due to its high adsorption capacity. However, its use is limited due to its high cost, and this has led to a search for cheaper substitutes. In terms of environmental protection, the utilization of these types of waste has sparked the development of processes for the production of carbon adsorbents based on plants and 
agricultural waste. Both the nature of the precursors and the production process strongly influence the porous structure and adsorption properties of the resulting activated carbons. The adsorption characteristics of activated carbon are determined by its pore structure (magnitude and distribution of pore volume) and surface chemistry (type and quality of surface-bound heteroatomic functional groups) [8]. Activated carbon can be prepared from a large number of sources, such as palm shells, wood, coconut shells, coal, carbon fibers and pitch [9]. Activated carbon can adsorb molecules from both liquid and gaseous phases depending on the specific surface area, pore size distribution, and surface functional groups (also denoted as surface complexes). Applications of activated carbon include drinking water purification, wastewater treatment, sweetener discoloration, food and chemical processing, solvent recovery, gasoline emission control, cigarette filters and as a treatment for industrial emission gas [10].

The aim of this research was the investigation of the methylene blue (MB) removal ability from aqueous solutions by activated carbon prepared from Sambucus nigra L. (SNL) that was chemically impregnated with $\mathrm{KHCO}_{3}$. The $\mathrm{pH}$, amount of adsorbent, and time of contact of activated carbon from SNL were investigated and results were compared to Merck activated carbon and an actual sample.

\section{Material and Methods}

\subsection{Preparation of modified activated carbon}

The SNL plant was used as the starting material. It was collected from the north of Iran. The stem of plant was burnt and then screened though a $120 \mathrm{~nm}$ sieve. The produced carbon $(1 \mathrm{~g})$ was chemically impregnated with $\mathrm{KHCO}_{3}(20 \%)$. The mixture was activated in five different furnaces (Table 1). The obtained carbon was then washed with hot distilled water. They were dried at $50-80^{\circ} \mathrm{C}$ in a thermostatically controlled oven and were then filtered and analyzed using a UV spectrophotometer (Shimadzu, UV1101, Japan).

The highest adsorption capacity of MB observed in a furnace with three continuous time and temperature steps (Fig. 1) was found in No. 5. These values were $30 \mathrm{~min}$ at $200^{\circ} \mathrm{C}, 60 \mathrm{~min}$ at $500^{\circ} \mathrm{C}, 30 \mathrm{~min}$ at $800^{\circ} \mathrm{C}$.

Therefore, the remaining adsorption experiments were carried out using these optimum times and temperatures in a furnace.

Table 1. Three-step preparation process at different times and temperatures

\begin{tabular}{ccccccc} 
No. & Time & Temp. & Time & Temp. & Time & Temp. \\
\hline 1 & $30 \min$ & $200^{\circ} \mathrm{C}$ & $60 \min$ & $400^{\circ} \mathrm{C}$ & $15 \min$ & $700^{\circ} \mathrm{C}$ \\
\hline 2 & $30 \min$ & $200^{\circ} \mathrm{C}$ & $60 \min$ & $500^{\circ} \mathrm{C}$ & $15 \min$ & $700^{\circ} \mathrm{C}$ \\
\hline 3 & $30 \min$ & $200^{\circ} \mathrm{C}$ & $60 \min$ & $600^{\circ} \mathrm{C}$ & $15 \min$ & $700^{\circ} \mathrm{C}$ \\
\hline 4 & $30 \min$ & $200^{\circ} \mathrm{C}$ & $60 \min$ & $500^{\circ} \mathrm{C}$ & $30 \min$ & $700^{\circ} \mathrm{C}$ \\
\hline 5 & $30 \min$ & $200^{\circ} \mathrm{C}$ & $60 \min$ & $500^{\circ} \mathrm{C}$ & $30 \min$ & $800^{\circ} \mathrm{C}$ \\
\hline
\end{tabular}

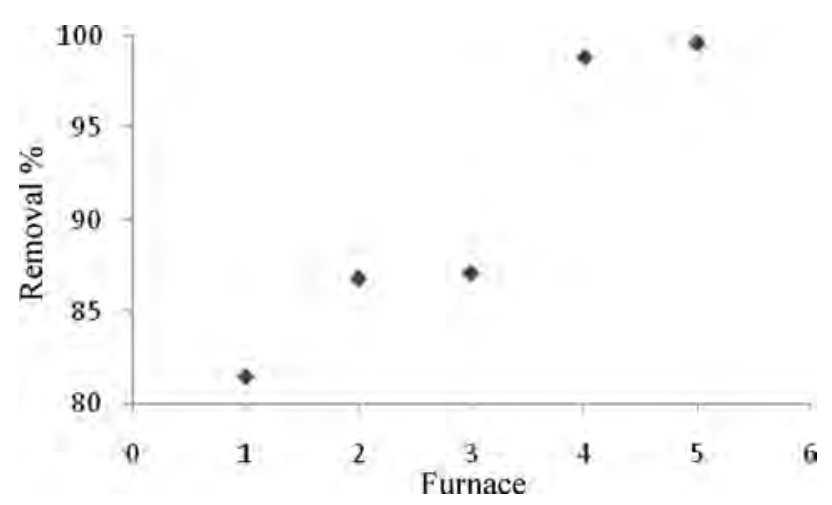

Fig. 1. Removal of methylene blue in five different furnaces.<smiles>CN(C)c1ccc2nc3ccc(N(C)C)cc3[s+]c2c1</smiles>

Fig. 2. Chemical structure of methylene blue.

\subsection{Preparation of the adsorbate}

MB (Fig. 2), a basic dye used as the model adsorbate in the present study, is a monovalent cationic dye. It has a molecular formula of $\mathrm{C}_{16} \mathrm{H}_{18} \mathrm{~N}_{3} \mathrm{SCl}$ and a molecular weight of 319.86 (g/ mol). It was used as an adsorbate without any purification. A stock solution of $1000 \mathrm{mg} / \mathrm{L}$ was prepared by dissolving an appropriate quantity of MB. The working solutions were prepared by diluting the stock solution with distilled water to procure the appropriate concentration of the working solutions. The chemical structure of MB is shown in Fig. 2. The concentration of MB was determined using a UV-Vis spectrophotometer at a wavelength of $620 \mathrm{~nm}$.

\subsection{Effect of $\mathrm{pH}$}

The $\mathrm{pH}$ of the solution from which adsorption occurs may influence the extent of adsorption. The $\mathrm{pH}$ affects adsorption in that it governs the degree of ionization of the acidic and basic compounds. In general, the initial $\mathrm{pH}$ value may enhance or depress the uptake. This is attributed to the change in the charge of the adsorbent surface with the change in the $\mathrm{pH}$ value [8]. In this work, the effect of the $\mathrm{pH}$ on the adsorption of $\mathrm{MB}$ by activated carbon derived from $\mathrm{SNL}$ was studied over a $\mathrm{pH}$ range of 3 to 12 . In the experiments, $0.035 \mathrm{~g}$ of activated carbon was added to $50 \mathrm{~mL}$ volumes of $\mathrm{MB}$ aqueous solution having an initial concentration $25.35 \mathrm{mg} / \mathrm{L}$ for a constant sorption time of 10 min. The adsorption behavior of the activated carbon of SNL was studied by $q e(\mathrm{mg} / \mathrm{g})$ and was calculated by the following mass balance relationship:

$$
q e=\left(C_{0}-C_{e}\right) \frac{V}{W}
$$

Here, $C_{0}$ and $C_{\mathrm{e}}$ are the initial and equilibrium liquidphase concentrations of dyes, respectively $(\mathrm{mg} / \mathrm{L}), V$ the volume of the solution (L), and $W$ the weight of the dry SNL used (g). 
Table 2. Characteristics of the activated carbon derived from SNL

\begin{tabular}{ccc} 
Multipoint BET $\left(\mathrm{m}^{2} / \mathrm{g}\right)$ & $\begin{array}{c}\text { BJH pore volume } \\
(\mathrm{cc} / \mathrm{g}) \\
(\text { desorption isotherm) }\end{array}$ & $\begin{array}{c}\text { BJH pore diameter } \\
(\mathrm{nm})\end{array}$ \\
\hline 426.9 & 0.126 & 1.186 \\
\hline
\end{tabular}

SNL: Sambucus nigra L., BET: Brunauer-Emmett-Teller, BJH: BarrettJoyner-Halenda.

\subsection{Effect of adsorbent dosage}

The effect of activated carbon derived from the SNL dosage on the adsorption process was investigated varying the adsorbent dosage from $0.015 \mathrm{~g} / 50 \mathrm{~mL}-0.055 \mathrm{~g} / 50 \mathrm{~mL}$ in the MB solutions. The mixture was agitated in a shaker for $10 \mathrm{~min}$ and the samples were then filtered and centrifuged. They were subsequently analyzed for the remaining MB concentration at a wavelength $620 \mathrm{~nm}$.

\subsection{Characterization of the activated carbon af- ter the preparation of modified activated carbon}

The Brunauer-Emmett-Teller (BET) method was used to calculate the surface area. The total pore volume $\left(\mathrm{v}_{\text {total }}\right)$ and the average pore diameter $\left(\mathrm{d}_{\mathrm{av}}\right)$ were derived from the Barrett-JoynerHalenda (BJH) method.

The BET surface area of activated carbon fiber derived from SNL as used in this paper was $426.9\left(\mathrm{~m}^{2} / \mathrm{g}\right)$ with a total pore volume of $0.126(\mathrm{cc} / \mathrm{g})$. The average pore diameter of SNL was found to be $1.186 \mathrm{~nm}$. Table 2 shows the characteristics of the activated carbon derived from SNL.

\subsection{Effect of contact time}

The effect of the contact time on the adsorption of MB on the activated carbons from SNL and Merck was studied. A $0.035 \mathrm{~g}$ sample of activated carbon derived from SNL was added to 50 $\mathrm{mL}$ of $\mathrm{MB}$ solution and agitated in a shaker in 1-30 min. The experiments were carried out at an initial MB concentration of $25.35 \mathrm{ppm}$. The samples were withdrawn at a suitable time interval, filtered, and centrifuged and the filtrate was analyzed for the remaining MB concentration spectrophotometrically at $620 \mathrm{~nm}$.

\subsection{Adsorption kinetics}

The adsorption kinetics of MB on activated carbon derived from SNL can be studied by applying a pseudo-first-order and pseudo-second-order rate equation of the types typically used to determine the adsorption of an adsorbate from an aqueous solution. These are expressed below.

$$
\begin{aligned}
& \ln \left(q_{e}-q_{t}\right)=\ln q_{e}-k_{a d} t \\
& \frac{t}{q_{t}}=\frac{1}{k_{a d} q_{e}^{2}}+\frac{1}{q_{e}} t
\end{aligned}
$$

In these equations, $\mathrm{q}_{\mathrm{e}}$ and $\mathrm{q}_{\mathrm{t}}$ are the amount of dye adsorbed per unit mass of the adsorbent $(\mathrm{mg} / \mathrm{g})$ at the equilibrium time and at time $t$, respectively, and $\mathrm{k}_{\mathrm{ad}}$ is the rate constant [11].
$0.035 \mathrm{~g}$ of activated carbon derived from SNL was added to $50 \mathrm{~mL}$ of MB solution (25.35 ppm) and the mixture was agitated in a shaker for different times, after which it was filtered. The remaining MB concentration filtrates were analyzed with a spectrophotometer at $620 \mathrm{~nm}$. This experiment was also carried out using Merck activated carbon.

\subsection{Adsorption isotherm}

Equilibrium adsorption isotherm studies are required in the screening of a sorbent for potential use as a form of wastewater treatment. This process can help to evaluate the affinity of a sorbent for a particular sorbate [12].

The experimental data results were analyzed by means of Langmuir, Freundlich, Temkin and Dubinin-Radushkevich (DR) isotherm equations. The Langmuir equation can be applied for the monolayer sorption onto a surface of a finite number of identical sites. The linearized form of the Langmuir isotherm is presented by the following equation [13]:

$$
\frac{1}{q_{e}}=\frac{1}{q_{\max }}+\left(\frac{1}{K_{L} q_{\max }}\right)\left(\frac{1}{C_{e}}\right)
$$

Here, $c_{e}$ is the equilibrium concentration $(\mathrm{mg} / \mathrm{L}), \mathrm{q}_{\mathrm{e}}$ is the adsorption capacity at equilibrium $(\mathrm{mg} / \mathrm{g}), \mathrm{k}_{\mathrm{L}}$ denotes the Langmuir adsorption constant $(\mathrm{L} / \mathrm{mg})$ and $\mathrm{q}_{\max }$ is the theoretical maximum adsorption capacity $(\mathrm{mg} / \mathrm{g})$ [14].

The sorption of MB was carried out at different initial MB concentrations ranging from 8.45 to $59.15 \mathrm{ppm}$; optimum conditions of all pertinent factors were used.

The essential characteristics of the Langmuir isotherm can be expressed in terms of the dimensionless constant separation factor $\mathrm{R}_{\mathrm{L}}$, as determined by the following equation:

Table 3. Comparison of the coefficients isotherm parameters by MB adsorption onto SNL and Merck AC

\begin{tabular}{cccc} 
Isotherm & $\begin{array}{c}\text { Constant } \\
\text { parameters }\end{array}$ & $\begin{array}{c}\text { Sambucus } \\
\text { nigra L. (AC) }\end{array}$ & Merck (AC) \\
\hline \multirow{4}{*}{ Langmuir } & $\mathrm{q}_{\max }(\mathrm{mg} / \mathrm{g})$ & 62.5 & 333.33 \\
& $\mathrm{~K}_{\mathrm{L}}(\mathrm{Lit} / \mathrm{mg})$ & 266.67 & 33.33 \\
& $\mathrm{R}_{\mathrm{L}}$ & $1.48 \times 10^{-4}$ & $1.18 \times 10^{-3}$ \\
& $\mathrm{R}^{2}$ & 0.673 & 0.936 \\
\hline \multirow{3}{*}{ Freundlich } & $\mathrm{K}_{\mathrm{F}}$ & 101.86 & 1629.3 \\
& $\mathrm{~N}$ & 3.98 & 1.5 \\
& $\mathrm{R}^{2}$ & 0.774 & 0.555 \\
\hline \multirow{2}{*}{ Temkin } & $\mathrm{A}(\mathrm{Lit} / \mathrm{mg})$ & 3229.23 & 1317.9 \\
& $\mathrm{~b}(\mathrm{~J} / \mathrm{mg})$ & 232.64 & 94.67 \\
& $\mathrm{R}^{2}$ & 0.926 & 0.739 \\
\hline Dubinin- & $\mathrm{K}(\mathrm{J} 2)$ & $6 \times 10^{-9}$ & $1 \times 10^{-8}$ \\
Radushkevich & $\mathrm{Qm}(\mathrm{mg} / \mathrm{g})$ & 77.71 & 304.6 \\
& $\mathrm{R}^{2}$ & 0.771 & 0.604 \\
\hline
\end{tabular}

MB: methylene blue, SNL: Sambucus nigra L., AC: activated carbon. 


$$
R_{L}=\frac{1}{\left(1+K_{L} \cdot C_{0}\right)}
$$

Here, $\mathrm{C}_{0}$ is the highest initial concentration of the adsorbate $(\mathrm{mg} / \mathrm{L})$ and $\mathrm{k}_{\mathrm{L}}$ is the Langmuir constant $(\mathrm{L} / \mathrm{mg})$. The value of $R_{L}$ indicates the shape of the isotherm-whether it is unfavorable $\left(R_{L}>1\right)$, linear $\left(R_{L}=1\right)$, favorable $\left(0<R_{L}<1\right)$ or irreversible $\left(R_{L}=0\right) . R_{L}$ values between 0 and 1 indicate favorable adsorption.

The Freundlich isotherm is derived by assuming a heterogeneous surface with a non-uniform distribution of heat of adsorption over the surface.

$$
q_{e}=K_{F} \cdot C_{e}^{1 / n}
$$

In this equation, $\mathrm{K}_{\mathrm{F}}$ is the adsorption capacity at the unit concentration and $1 / \mathrm{n}$ is the adsorption intensity. $1 / \mathrm{n}$ values indicate the type of isotherm - whether it is irreversible $(1 / \mathrm{n}=0)$, favorable $(0<1 / \mathrm{n}<1)$, or unfavorable $(1 / \mathrm{n}>1)$. Eq. (6) can be rearranged into a linear form [15]:

$$
\log q_{e}=\log K_{F}+\left(\frac{1}{n}\right) \log C_{e}
$$

The linear form of the D-R isotherm equation can be expressed as [16],

$$
\ln q_{e}=\operatorname{Ln} Q_{m}-K \varepsilon^{2}
$$

where $\mathrm{Q}_{\mathrm{m}}$ is the theoretical monolayer saturation capacity $(\mathrm{mg} / \mathrm{g}), \mathrm{K}$ is the D-R model constant $\left(\mathrm{mg}^{2} / \mathrm{J}^{2}\right)$, and $\varepsilon$ is the Polanyi potential. The latter value is expressed as follows:

$$
\varepsilon=R T \operatorname{Ln}\left(1+\frac{1}{C_{e}}\right)
$$

Ln $\mathrm{q}_{\mathrm{e}}$ vs. $\varepsilon^{2}$ was plotted at different temperatures for both the SNL and Merck activated carbon, as shown in Fig. 3. A list of the parameters obtained together with the $\mathrm{R}^{2}$ values are given in Table 3.

\subsection{Real sample}

The adsorption of MB by activated carbon from SNL with $\mathrm{KHCO}_{3}$ was investigated using a textile factory effluent sample and the results were compared to those from a laboratory sam-

\begin{tabular}{|c|c|c|c|}
\hline Samples & $\mathrm{C}_{0}$ & $\mathrm{C}_{\mathrm{e}}$ & Removal \% \\
\hline Laboratory sample & $25.35 \mathrm{ppm}$ & $0.0129 \mathrm{ppm}$ & $99.94 \%$ \\
\hline $\begin{array}{c}\text { Textile effluent } \\
\text { sample }\end{array}$ & $25.35 \mathrm{ppm}$ & $0.4907 \mathrm{ppm}$ & $98.06 \%$ \\
\hline
\end{tabular}
ple. Table 4 shows the comparison of the percentage adsorption of $\mathrm{MB}$ with the two samples. According to this table, the percentages of adsorption of $\mathrm{MB}$ using the activated carbon from SNL were identical for the two samples.

MB: methylene blue.

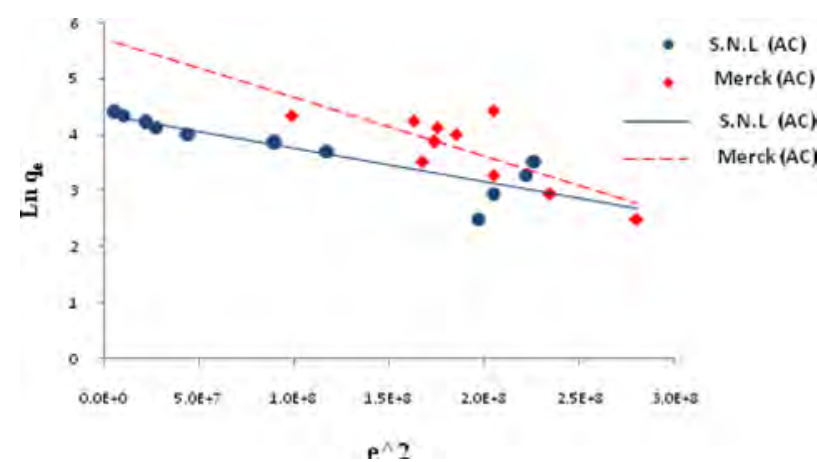

Fig. 3. Dubinin-Radushkevich model for the adsorption of methylene blue by S.N.L (AC) and Merck (AC). S.N.L: Sambucus nigra L., AC: activated carbon.

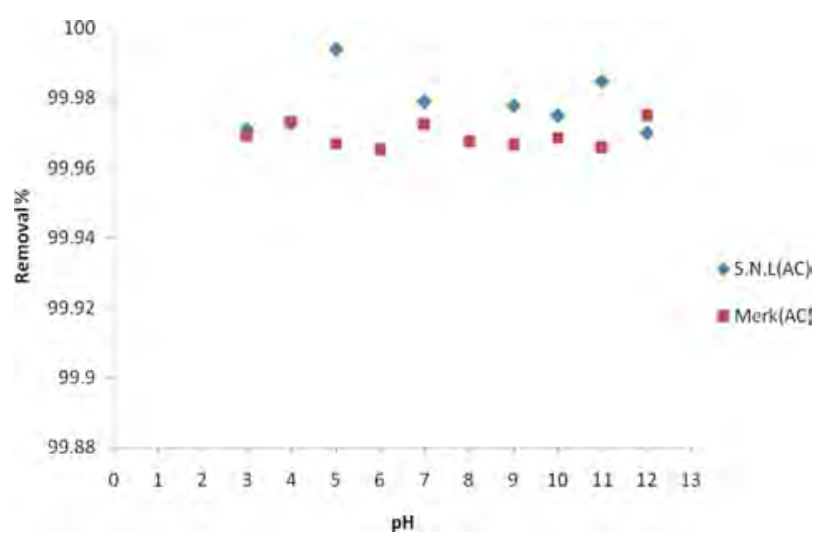

Fig. 4. Effect of $\mathrm{pH}$ on the removal percentage of methylene blue for different activated carbons. S.N.L: Sambucus nigra L.

\section{Results and Discussion}

\subsection{Effect of the $\mathrm{pH}$}

Fig. 4 shows the effect of the $\mathrm{pH}$ on the removal percentage of MB dye for the activated carbon derived from SNL and from Merck activated carbon. The sorption at $\mathrm{pHs}$ ranging from 3 to 11 was remarkable, and there was no significant difference in the dye concentration remaining when the $\mathrm{pH}$ was increased because the solution $\mathrm{pH}$ was higher than the $\mathrm{pH}_{\mathrm{zpc}}$ value [17].

\subsection{Effect of the adsorbent dosage}

Fig. 5 shows the effect of the adsorbent dosage on the adsorption of MB for activated carbon derived from SNL and for Merck activated carbon. It was observed that the removal of MB increased to 0.045 and then remained nearly constant. The increase in the color removal percentage was due to the increase in the size of the available sorption surface.

\subsection{Effect of the contact time}

Equilibrium levels were mostly achieved in $10 \mathrm{~min}$. A slight increase occurred during the next 10 min. Fig. 6 shows the effect of the contact time on the adsorption of $\mathrm{MB}$ for activated carbon derived from SNL and for the Merck activated carbon. 


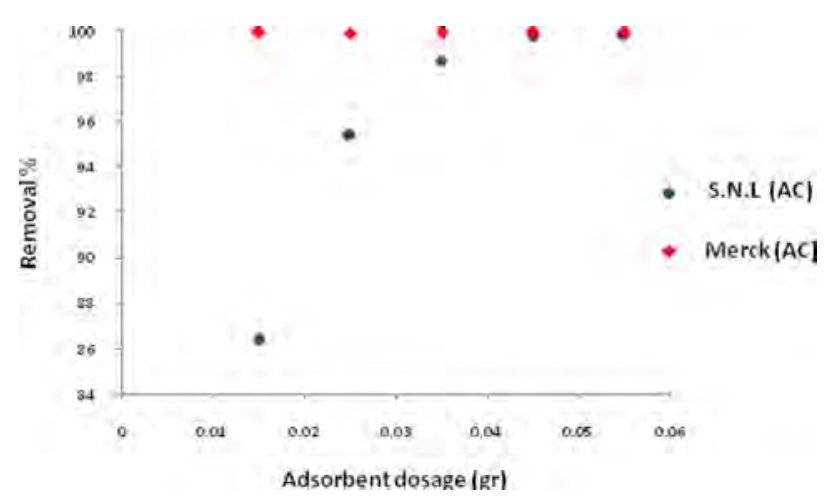

Fig. 5. Effect of the adsorbent dosage on the removal percentage of methylene blue for different activated carbons. S.N.L: Sambucus nigra L.

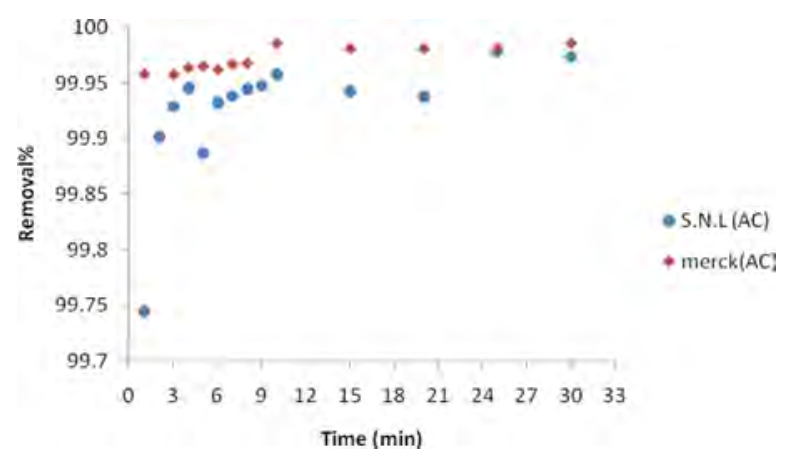

Fig. 6. Effect of the agitating time on the percentage removal of methylene blue by different activated carbons. S.N.L: Sambucus nigra L.

\subsection{Adsorption kinetics}

Figs. 7 and 8 show the pseudo-first-order and pseudo-secondorder plots, respectively. As shown, the pseudo-second-order plot gives a straight line with a correlation coefficient $\mathrm{R}^{2}$ of 1 for SNL (activated carbon) and 1 for Merck (activated carbon), indicating that the applicability of the pseudo-second-order equation was better than that of the pseudo-first-order plot, with $\mathrm{R}^{2}$ $=0.376$ for SNL (activated carbon) and $\mathrm{R}^{2}=0.272$ for Merck (activated carbon) only. Table 5 shows the kinetics constants for the pseudo-first and pseudo-second-order models.

\subsection{Adsorption isotherm}

According to the $\mathrm{R}^{2}$ values, the fitting of the Temkin isotherm to the experimental data is better than that of the other isotherms

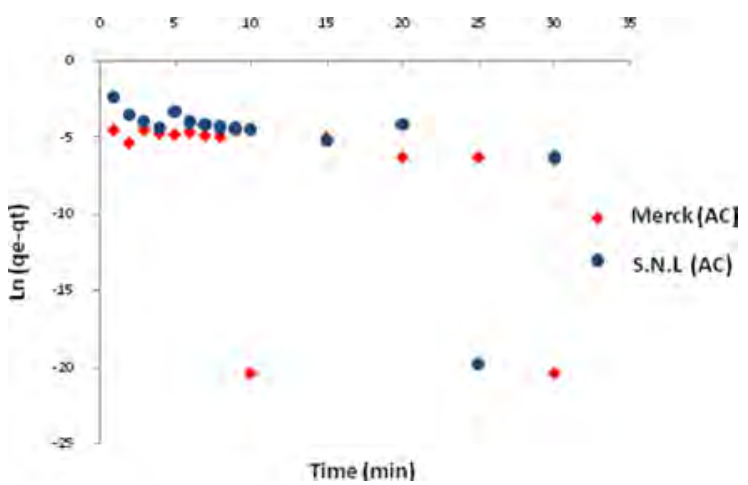

Fig. 7. Pseudo-first-order plot for methylene blue adsorption by different activated carbons. S.N.L: Sambucus nigra L.

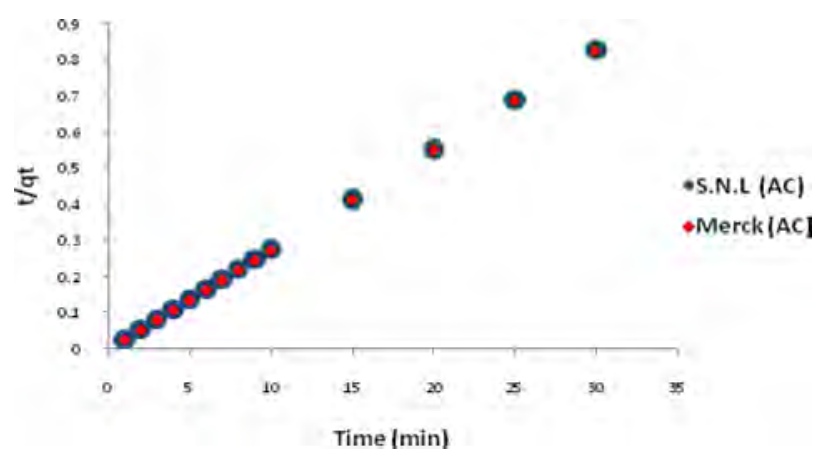

Fig. 8. Pseudo-second-order plot for methylene blue adsorption by different activated carbons. S.N.L: Sambucus nigra L.

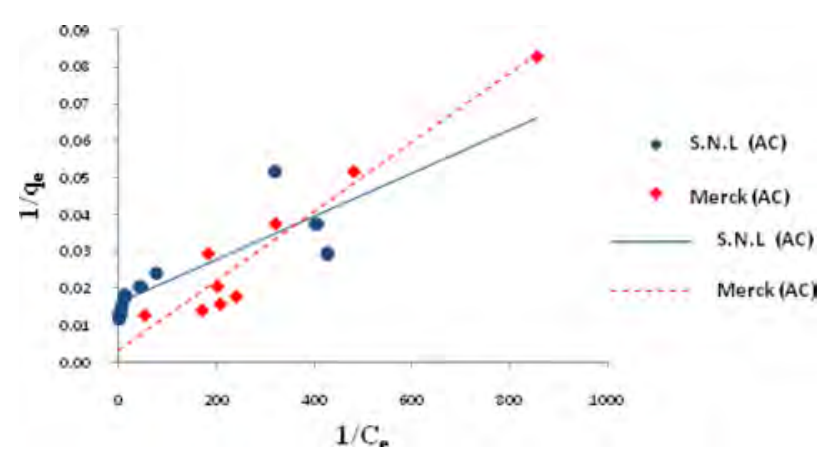

Fig. 9. Langmuir model for the adsorption of methylene blue by S.N.L (AC) and Merck (AC). S.N.L: Sambucus nigra L., AC: activated carbon.

in this study for SNL. In addition, the fitting of the Langmuir isotherm to the experimental data is better than that noted with

Table 5. Kinetics constants for pseudo-first and pseudo-second-order models

\begin{tabular}{ccccccc}
\hline \multirow{2}{*}{ Activated carbon } & \multicolumn{3}{c}{ Methylene blue } \\
\cline { 2 - 7 } & $\mathrm{K}(1 / \mathrm{min})$ & $\mathrm{q}$ Pseudo-first-order & \multicolumn{3}{c}{ Pseudo-second-order } \\
\hline SNL & 0.291 & 0.0936 & 0.376 & $\mathrm{~K}(\mathrm{~g} / \mathrm{mg}$ min) & $\mathrm{q}_{\mathrm{e}}(\mathrm{mg} / \mathrm{g})$ & $\mathrm{R}^{2}$ \\
\hline Merck & 0.328 & 0.0196 & 0.272 & 24.41 & 37.04 & 1 \\
\hline
\end{tabular}

SNL: Sambucus nigra L. 


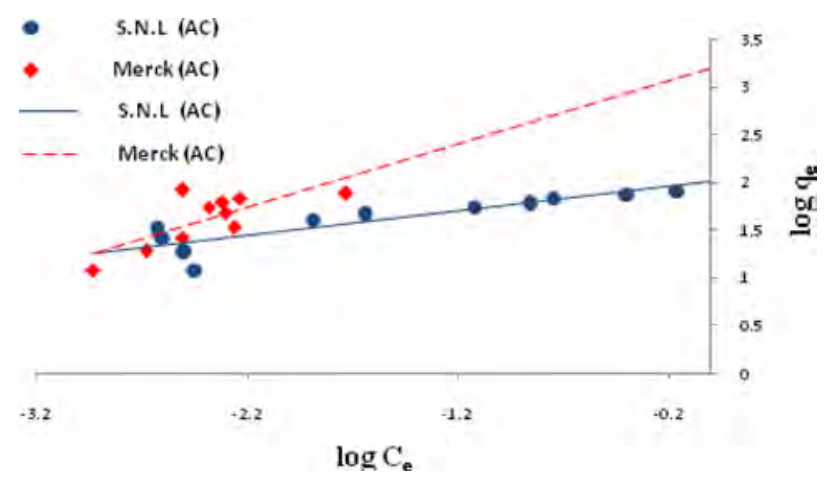

Fig. 10. Freundlich model for the adsorption of methylene blue by S.N.L (AC) and Merck (AC). S.N.L: Sambucus nigra L., AC: activated carbon.

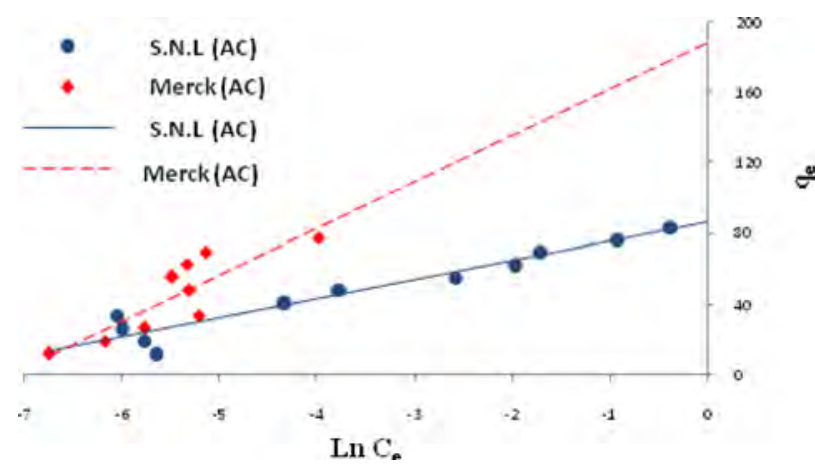

Fig. 11. Temkin model for the adsorption of methylene blue by S.N.L (AC) and Merck (AC). S.N.L: Sambucus nigra L., AC: activated carbon.

the other isotherms in this study for the Merck activated carbon. Figs. 3, 9-11 show the Langmuir, Freundlich, Temkin and D-R models, respectively, for the adsorption of MB by SNL and Merck activated carbon.

\section{Conclusions}

This study investigated the adsorption mechanism of MB (a cationic dye) on activated carbon samples from an aqueous solution as a function of the $\mathrm{pH}$, amount of adsorbent, contact time, adsorption kinetics and adsorption isotherm. The results were compared to those using Merck activated carbon and a real sample. According to the results, prepared activated carbon can be used as a low-cost adsorbent comparable to commercial forms of activated carbon for the removal of textile dyes from textile wastewater processes. The cost is low because SNL is a weed in the north of Iran. The highest adsorption capacities were observed in three continuous steps at the times and temperatures of $30 \mathrm{~min}$ at $200^{\circ} \mathrm{C}, 60 \mathrm{~min}$ at $500^{\circ} \mathrm{C}, 30 \mathrm{~min}$ at $800^{\circ} \mathrm{C}$. According to the results, the $\mathrm{pH}$ did not have a significant effect on the color removal activity. The highest adsorption capacity was obtained when $0.035 \mathrm{~g}$ of adsorbent. The adsorption equilibrium for color removal was reached within $10 \mathrm{~min}$. The isotherm data was well fitted to the Temkin model, and the sorption process obeyed the pseudo-second-order kinetic model.

\section{References}

[1] Abdelwahab O. Evaluation of the use of loofa activated carbons as potential adsorbents for aqueous solutions containing dye. Desalination, 222, 357 (2008). http://dx.doi.org/10.1016/j.desal.2007. 01.146 .

[2] Ofomaja AE, Ho YS. Effect of temperatures and $\mathrm{pH}$ on methyl violet biosorption by Mansonia wood sawdust. Bioresour Technol, 99, 5411 (2008). http://dx.doi.org/10.1016/j.biortech.2007.11.018

[3] Tunali S, Ozcan AS, Ozcan A, Gedikbey T. Kinetics and equilibrium studies for the adsorption of Acid Red 57 from aqueous solutions onto calcined-alunite. J Hazard Mater, 135, 141 (2006). http:// dx.doi.org/10.1016/j.jhazmat.2005.11.033.

[4] Kadirvelu K, Palanival M, Kalpana R, Rajeswari S. Activated carbon from an agricultural by-product, for the treatment of dyeing industry wastewater. Bioresour Technol, 74, 263 (2000). http://dx.doi. org/10.1016/S0960-8524(00)00013-4.

[5] Kavitha D, Namasivayam C. Capacity of activated carbon in the removal of acid brilliant blue: determination of equilibrium and kinetic model parameters. Chem Eng J, 139, 453 (2008). http:// dx.doi.org/10.1016/j.cej.2007.08.011

[6] Arami M, Yousefi Limaee N, Mahmoodi NM. Investigation on the adsorption capability of egg shell membrane towards model textile dyes. Chemosphere, 65, 1999 (2006). http://dx.doi.org/10.1016/j. chemosphere.2006.06.074.

[7] Demirbas A. Heavy metal adsorption onto agro-based waste materials: a review. J Hazard Mater, 157, 220 (2008). http://dx.doi org/10.1016/j.jhazmat.2008.01.024.

[8] Aygun A, Yenisoy-Karakaş S, Duman I. Production of granular activated carbon from fruit stones and nutshells and evaluation of their physical, chemical and adsorption properties. Microporous Mesoporous Mater, 66, 189 (2003). http://dx.doi.org/10.1016/j. micromeso.2003.08.028.

[9] Manoochehri M, Rattan VK, Khorsand A, Panahi HA. Capacity of activated carbon derived from agricultural waste in the removal of reactive dyes from aqueous solutions, Carbon Lett, 11, 169 (2010). http://dx.doi.org/10.5714/CL.2010.11.3.169

[10] Joseph CG, Bono A, Krishnaiah D, Soon KO. Mater Sci (Medziagotyra), 13, 83 (2007).

[11] Hameed BH. Spent tea leaves: a new non-conventional and lowcost adsorbent for removal of basic dye from aqueous solutions. J Hazard Mater, 161, 753 (2009). http://dx.doi.org/10.1016/j. jhazmat.2008.04.019.

[12] Oladoja NA, Aboluwoye CO, Oladimeji YB, Ashogbon AO, Otemuyiwa IO. Studies on castor seed shell as a sorbent in basic dye contaminated wastewater remediation. Desalination, 227, 190 (2008). http://dx.doi.org/10.1016/j.desal.2007.06.025

[13] Ho YS. Isotherms for the sorption of lead onto peat: comparison of linear and non-linear methods. Polish J Environ Stud, 15, 81 (2006).

[14] Ho YS. Second-order kinetic model for the sorption of cadmium onto tree fern: a comparison of linear and non-linear methods. Water Res, 40, 119 (2006). http://dx.doi.org/10.1016/j.watres.2005.10.040.

[15] Khaled A, El Nemr A, El-Sikaily A, Abdelwahab O. Treatment of artificial textile dye effluent containing Direct Yellow 12 by orange peel carbon. Desalination, 238, 210 (2009). http://dx.doi org/10.1016/j.desal.2008.02.014 
[16] Karaca S, Gurses A, Acıkyıldız M, Ejder M. Adsorption of cationic dye from aqueous solutions by activated carbon. Microporous Mesoporous Mater, 115, 376 (2008). http://dx.doi.org/10.1016/j. micromeso.2008.02.008
[17] Waranusantigul P, Pokethitiyook P, Kruatrachue M, Upatham ES. Kinetics of basic dye (methylene blue) biosorption by giant duckweed (Spirodela polyrrhiza). Environ Pollut, 125, 385 (2003). http://dx.doi.org/10.1016/S0269-7491(03)00107-6. 